\title{
A chorographia de Laudelino Freire (1898)
}

\author{
Vera Maria dos Santos \\ Simone Silveira Amorim \\ Éverton Gonçalves de Ávila
}

Resumo: Este artigo analisa a obra Quadro Chorographico de Sergipe do professor e advogado Laudelino de Oliveira Freire sob os seguintes aspectos: a intenção do autor, o conteúdo e os juízos da imprensa. Utilizou-se das seguintes fontes para a realização deste trabalho: a primeira e a segunda edição do livro, Quadro Chorographico de Sergipe, o Dicionário Bio-bibliográfico de Armindo Guaraná e a Collecção das Leis, Decretos e Actos do Estado de Sergipe, dos anos de 1897-1898, além das fontes bibliográficas. Os trabalhos que referenciam essa análise são aqueles que entendem o livro didático como objeto cultural que guarda as marcas de seu uso. O Quadro Chorographico de Sergipe, publicado em 1898, foi uma obra importante para a mocidade sergipana, considerando o tempo e o espaço em que foi produzido.

Palavras-chave: Livro-didático. Materialidade. Circulação. História da educação. Quadro chorographico de Sergipe.

\section{The Chorographia of Laudelino Freire (1898)}

Abstract: This article analyzes the work Chorographic Picture of Sergipe by the professor and lawyer Laudelino de Oliveira Freire under the following aspects: the intention of the author, the content and judgments of the press. In order to carry out this work, the following sources were used: the first and second edition of the book Chorographic Picture of Sergipe, the Bio-bibliographic Dictionary of Armindo Guaraná and the Collection of Laws, Decrees and Acts of the State of Sergipe, from 1897 to 1898, in addition to bibliographical sources. The works used to refer this analysis are those that understand the didactic book as a cultural object which keeps the marks of its use. The Chorographic Picture of Sergipe, published in 1898, was an important work for Sergipe youth, considering the time and space on which it was produced.

Keywords: Didactic book. Materiality. Circulation. History of education. Chorographic picture of Sergipe.

Quaestio, Sorocaba, SP, v. 19, n. 2, p. 455-470, ago. 2017. 


\section{Introdução}

No Mestrado, trabalhei com os livros didáticos de Geografia e, com a sua finalização, muitos livros ficaram pelo caminho, sem o devido aprofundamento. O Quadro Chorographico de Sergipe, do advogado e professor Laudelino de Oliveira Freire, foi um deles. Agora decidi lançar luzes sobre esse impresso e partilhar com outros pesquisadores do Programa de Pósgraduação em Educação da Universidade Tiradentes. Esses pesquisadores trabalham, de algum modo, com jornais e com livros como objeto de estudo.

Assim compreendido, construímos as seguintes indagações: O que é Chorographia e em que se diferencia da Geografia? Temos algum indício da sua circulação em Sergipe? Qual a sua importância para a educação sergipana? Para responder as essas inquietações decidimos lançar luzes sobre esse objeto de estudo, de modo que possamos responder às interrogações propostas.

Analisar o Quadro Chorographico de Sergipe, sob três direções, que são: a intenção do autor, o conteúdo e os juízos da imprensa é o objetivo deste estudo, que se fundamenta na perspectiva da Nova História Cultural que, dentre outros objetos de estudo, abriu espaço também para a investigação do livro didático, que não era objeto relevante para a história tradicional.

O livro didático desempenha papel importante, impõe uma ordem, decifra e vulgariza os discursos disciplinares de uma época. O impresso didático

[...] além de contemplar a prescrição curricular oficial, constitui uma manifestação material e concreta do saber transformado para fins didáticos. Afora isso, oferece um ordenamento aos conteúdos e sugere diversas atividades pedagógicas para se trabalhar tais conteúdos (WUO, 2003, p. 308).

Sob tal perspectiva, o conceito de livro didático é tomado aqui a partir de autores que o consideram "como objeto material, diferente de outros tipos de escritos, cuja coerência e completude resultam de uma intenção intelectual ou estética" (CHARTIER, 2002, p. 110). De acordo com o que propõe Roger Chartier é importante compreender que "os livros são vistos aqui como produtores de um universo de inter-relações humanas que se estabelecem a partir das diversas e variáveis maneiras de se abordar a arte da leitura" (1999, p. 8). Ainda para esse autor, não existe separação entre a função do livro e a sua materialidade; muito pelo contrário, elas se completam, tornando-se realidades físicas e, assim, passam a existir.

Sob o mesmo olhar de Chartier, Munakata (1997) compreende o livro didático como objeto material, constituído basicamente de tinta e papel. É um tipo de livro transportado, 
constantemente, da casa do seu leitor para um lugar específico que se chama escola e, desta, para o ponto inicial - e isso quase diariamente.

Dentro dessa mesma perspectiva, Carvalho (2000) defende a ideia do livro como um objeto cultural que guarda as marcas de sua produção e de seus usos, sendo estas reveladoras de modelos, práticas e condicionamentos sociais que vigoraram numa determinada época na sociedade. É sob esse aporte teórico que as fontes serão analisadas e a pesquisa se desenvolverá.

Para a realização deste trabalho, utilizaram-se as seguintes fontes: a primeira edição (1898) e a segunda edição do livro (1902) “Quadro Chorographico de Sergipe”, de Laudelino de Oliveira Freire, o "Dicionário Bio-bibliográfico", de Armindo Guaraná; e, a Collecção das Leis, Decretos e Actos do Estado de Sergipe, dos anos de 1897-1898, fontes bibliográficas.

É importante observar que a capa exibe a nota de que o prefácio foi escrito pelo Barão do Rio Branco, um intelectual renomado, que tinha uma relação estreita com o professor Laudelino Freire.

É importante ressaltar que em Sergipe, chegamos ao período republicano sem que houvesse uma publicação didática de Chorographia ou Geografia local. No entanto, o processo de construção da identidade republicana insistia que os conteúdos da Geografia de Sergipe chegassem às escolas. Era necessária a veiculação dos ideais republicanos, sendo o livro didático um meio importante para a vulgarização desses ideais regeneradores da nação. Neste sentido, a instituição escolar republicana, através do impresso, impôs um sistema de regras, hábitos e comportamentos visando civilizar os infantes.

Em relação a esse momento, Souza (1998) ressaltou que a escola estava comprometida com a difusão dos valores republicanos e com a construção e consolidação do novo regime "É a escola da República e para a República” (p. 28). O projeto de educação integral da República envolvia os saberes elementares, as competências básicas de leitura, de escrita, de cálculo, a formação moral e cívica, a adoção do método intuitivo e, também, a utilização do livro didático.

Fazia-se urgente, pois, em Sergipe, a didatização dos conteúdos, de forma a permitir aos alunos a assimilação, de forma sistematizada, dos conteúdos culturais selecionados pela educação escolar. Neste sentido, a elaboração didática não se caracteriza apenas pela simples transposição e vulgarização do saber erudito para a instituição escolar, mas configura-se uma operação intelectual que cria conhecimento próprio e específico. Vê-se então o livro didático como espaço 
civilizador, que carrega os valores republicanos a serem transmitidos, sendo o difusor de um projeto de nação a ser construído por meio da educação escolar.

Com essa discussão surgiram os primeiros livros didáticos sergipanos de Chorographia, acompanhando um processo que podia ser observado em outras regiões do país. As Chorographias foram os primeiros livros escolares que reuniram os múltiplos geográficos e históricos da vida sergipana de forma didática.

\section{A intenção do autor}

Antes de iniciarmos a análise do livro, objeto deste artigo, é preciso entender quem foi Laudelino de Oliveira Freire, para depois compreendermos em que momento o ensino de Chorographia sergipana apareceu nos programas escolares. Conforme Guaraná, Laudelino de Oliveira Freire,

[...] filho de Felisbelo Firmo de Oliveira Freire e D. Rosa de Araújo Goes Freire, e irmão do Dr. Felisbelo Freire, nasceu a 26 de janeiro de 1873 na cidade do Lagarto. Iniciou os estudos preparatórios no Liceu Laranjeirense, dirigido pelo Professor Baltazar Goes, na cidade de Laranjeiras, concluindo-os na Escola Militar do Rio de Janeiro, onde fez todos os estudos de matemáticas superiores. Acometido de grave enfermidade teve de abandonar a vida militar para a qual não se sentia com vocação, resolvendo seguir a carreira de direito. Diplomou-se em 1895 em ciências sociais na Faculdade Livre de Direito do Rio de Janeiro, formando-se em 1902 em ciências jurídicas (GUARANÁ, 1925, p. 362).

Ainda seguindo as pegadas do dicionarista Guaraná (1925), Laudelino Freire, advogado de formação, foi também professor catedrático do Colégio Militar no Rio de Janeiro, onde também exerceu a advocacia e,

[...] foi eleito deputado à Assembléia Legislativa do seu Estado natal para as legislaturas de 1894-1895, 1896-1897 e 1898-1899. Em 1900 foi escolhido pelo Governo do Estado de Sergipe para Fiscal das Loterias dos Estados na Capital Federal. Presidiu o Grêmio Literário "24 de Julho" de Aracaju, e é sócio efetivo desde 1906, do Instituto da Ordem dos Advogados Brasileiros do Rio de Janeiro e do Instituto Histórico e Geográfico Brasileiro desde 1917 (GUARANÁ, 1925, p. 362).

Colaborou, conforme Guaraná (1925), em diversos periódicos de grande circulação no Rio de Janeiro e em Sergipe: "Brasiléia", revista, Rio de Janeiro, o "Republicano", "Comércio de Sergipe”, “O Estado de Sergipe”, “Almanaque Sergipano”. Aracaju, "O País”, "Jornal do Comércio", "Gazeta da Tarde”, “Almanaque Garnier", “Aspiração", "Progresso Educador", revista do Rio. Revista “Tobias e Ozório” - Escola Militar - Rio. 
De acordo com Guaraná (1925), Laudelino Freire fundou, juntamente com o Dr. Luis Carlos Duque Estrada, a Revista do Instituto Didático, em 1895, e foi redator chefe da "Revista Didática", cujo $1^{\circ}$ número apareceu em janeiro de 1902; organizou a Revista da Língua Portuguesa; arquivo de estudos relativos ao idioma e à literatura nacionais, publicação bimestral, sendo o $1^{\circ}$ número de setembro de 1919, com 202 páginas. Foi correspondente literário do "Diário de Pernambuco" e sócio correspondente do Instituto Histórico e Geográfico de Sergipe.

Foi um grande intelectual e, conforme Guaraná (1925), um dos nossos literatos mais operosos do Brasil; ocupou, na Academia Brasileira de Letras, a cadeira que vagou com a morte do Conselheiro Rui Barbosa. Na sua intensa atividade intelectual escreveu artigos, pareceres e livros, e traduziu diversos livros.

Laudelino Freire foi uma pessoa singular, mas, como afirmou Ginzburg, esta “[...] singularidade tinha limites bem precisos: da cultura do próprio tempo e da própria classe [...]" (GINZBURG, 1989, p. 27). Faleceu em 18 de junho de 1837.

Voltando à questão inicial deste item, que é: em que momento o ensino de Chorographia sergipana apareceu nos programas escolares? Nos programas escolares de 1881, encontramos a primeira referência ao ensino de Chorographia sergipana, na reforma proposta pelo presidente da Província, Inglês de Souza, que incluiu, para o quarto ano do ensino secundário, História dos Tempos Modernos, História do Brasil e Chorographia da Província de Sergipe. Em relação a esse fato, Nunes (1984) argumentou que muito embora a citada reforma não tenha se estabelecido, não se pode esquecer o caráter inovador da reforma proposta pelo então presidente, posto que trazia o estudo da "Chorographia da Província de Sergipe no qual era focalizado os aspectos geográficos, permitindo aos alunos melhor conhecer a sua terra" (NUNES, 1984, p. 151).

Após dezesseis anos de ausência nos programas, o ensino de Chorographia sergipana apareceu novamente, com a promulgação do Decreto $\mathrm{n}^{\mathrm{o}}$ 231, de 9 de julho de 1897 (SERGIPE, 1900, p. 227), que reformou, mais uma vez, a instrução pública e colocou a Chorographia no programa para as escolas públicas, do sexo masculino.

Nessas escolas exigiram-se leitura de Catecismo, Moral prática e Educação cívica aplicada, Recitação da vida dos grandes homens, Contos e poesias heroicas, que lançassem no espírito dos meninos o amor da pátria e a glória, noções de geografia geral e cosmografia, Chorographia do Brasil e especialmente de Sergipe. 
A partir da Lei $\mathrm{n}^{\mathrm{o}}$ 257, de 25 de novembro 1897, a cadeira de Chorographia foi anexada à de Geografia (SERGIPE, 1900a, p. 236). Entretanto, Andrade (2002) chamou a atenção para o fato de que, somente a partir de 1901, a Chorographia de Sergipe foi introduzida no programa da disciplina como obrigatória:

[...] constata-se a inserção da disciplina História de Sergipe a partir do ano de 1897, como matéria, do currículo das escolas públicas primárias. Quatro anos depois, verificase a introdução de Chorographia de Sergipe como obrigatória no programa das disciplinas. Ambas são encontradas como disciplinas obrigatórias no ano de 1916, [ano também, de] publicação da obra Meu Sergipe, [a disciplina Chorographia de Sergipe foi encontrada] no programa da Escola Normal, para formação do magistrado, quanto no programa das escolas primárias (ANDRADE, 2002, p. 50).

Seguindo o entendimento de Andrade (2002), foi em 1901 que a cadeira de Chorographia de Sergipe foi incluída no currículo da escola primária. Em relação ao livro, somente nove anos depois da proclamação da República, o advogado e professor do Colégio Militar do Rio de Janeiro, o sergipano, Laudelino de Oliveira Freire apresentou em 1898, para a "mocidade sergipana", O Quadro Chorographico de Sergipe.

Em relação ao ano de publicação do livro do professor Laudelino, vale chamar a atenção para o fato de outros estudiosos terem atribuído datas de publicação diferentes ao livro do sergipano, como foi o caso de José Calazans Brandão da Silva (1992), que em seu trabalho Aracaju e outros temas sergipanos, datou a obra como sendo de 1896. Mas até o final desta pesquisa não encontramos evidências de tal fato. Para afirmar que a obra do sergipano é de 1898, tomamos como parâmetro o Diccionario Bio-Bibliographico Sergipano, de Armindo Guaraná (1925), que citou que o livro saiu em 1898 e mencionou ainda que a segunda edição saiu em 1902, pela H. Garnier, com 176 páginas, seguidas de quadros e juízos da imprensa sobre a primeira edição, "consideravelmente aumentada".

Quando fizemos uma análise mais apurada das fontes encontramos as duas edições: a primeira datada de 1898 e a segunda de 1902, desmistificando toda a questão sobre o ano de publicação. Então concluímos que o referido livro foi publicado em 1898, sendo o segundo livro sergipano que reuniu os conhecimentos geográficos e históricos com fins didáticos.

Voltando ao objetivo da obra, a própria palavra "Quadro" sugere uma visão geral dos aspectos sergipanos, que aparecem nesse trabalho, de forma sistematizada. Essa obra de conteúdo corográfico, referente ao Estado que lhe "servio de berço", e circulou no cenário escolar sergipano, daquele tempo. Convém frisar que a primeira Chorographia do Estado de Sergipe é de 
autoria do baiano Luiz Carlos Silva Lisboa que em 29 de julho de 1896, teve a sua aprovação pelo Conselho da Instrução Pública, conforme consta no próprio livro, página 7. O sergipano Laudelino Freire tomou essa iniciativa um ano depois de Lisboa em 1898.

O livro mostra ser didático não somente pela intenção do autor ao apresentá-lo para a "mocidade sergipana", mas também, pelo que o livro expressa na sua materialidade: formato de um livro de bolso, tamanho 17,5 por $11 \mathrm{~cm}$, capa dura, letras serifadas, tamanho 12, tabela e ilustração, forma de dividir o texto e organização do conteúdo.

$\mathrm{Na}$ parte introdutória, o professor Laudelino dedicou o seu livro à mocidade sergipana. Apesar de o autor qualificar a sua obra como sendo meramente "descritiva" e de consolar-se por ele prestar algum serviço à mocidade do Estado: “Outro intuito não tem este livro, especialmente dedicado à mocidade sergipana, senão de prestar um pequeno serviço ao Estado que nos servio de berço" (FREIRE, 1898, p. IX). Pelo que consta na segunda edição, o livro foi adotado nas escolas do Estado daquele tempo.

O Barão do Rio Branco, a quem foi incumbida a tarefa de revisar as provas do Quadro Chorographico de Sergipe, em 1898, ao prefaciar a obra ressaltou:

É um compendio elementar e destinado à instrucção dos que ainda não pódem receber grande somma de informações scientificas, o seu livro é forçosamente resumido, mas mesmo assim, simples e despretencioso como é, elle constitue uma muito substancial descripção histórica e geographica d'esse canto tão interessante da bella pátria brazileira. É bem patente nas paginas que acabo de ler o trabalho de condensação intelligente que ellas necessitaram.

Faltam-me os elementos para a crítica minuciosa das informações assim compendiadas. Apenas posso apreciar as grandes linhas da sua exposição, e essas merecerão applauso de qualquer douto na matéria [...] (BARÃO DO RIO BRANCO, 1898, p. XIV).

Ainda no texto do Barão do Rio Branco é possível perceber a dificuldade em se fazer um trabalho dessa natureza no Brasil à época, considerando a falta de documentação, de dados estatísticos e de estudos geográficos que pudessem servir de subsídio:

Quanto à estatística, nem é bom falar, pois sómente n'estes últimos vinte e cinco annos começámos a comprehender, e de modo muito imperfeito, a sua utilidade. Quanto à explorações do nosso interior, a levantamentos de plantas parciaes e a documentos cartographicos recentes, a nossa pobreza é muito grande. Ainda hoje a Brasilioe Geographica tabula Nova, terminada por George Marggraff em 1643, é o documento mais minucioso e interessante que possuímos sobre as terras das zonas marítima que se extende de Sergipe ao Rio Grande do Norte. O mappa da província de S. Pedro do Rio Grande do Sul, publicado em 1839 pelo Visconde de S. Leopoldo, continúa sendo à muitos respeitos o mais completo e exacto dos que temos sobre essa parte do Brazil (BARÃO DO RIO BRANCO, 1898, p. XV). 
Para o Barão do Rio Branco o esforço de Laudelino de Oliveira Freire foi enorme frente as dificuldades apontadas e falta de documentação existente, como conteúdo, mapas. Mas não podemos esquecer que Laudelino era professor e um grande pesquisador à sua época.

Figura 1 - Capa do livro didático de Laudelino de Oliveira Freire, Quadro Chorographico de Sergipe

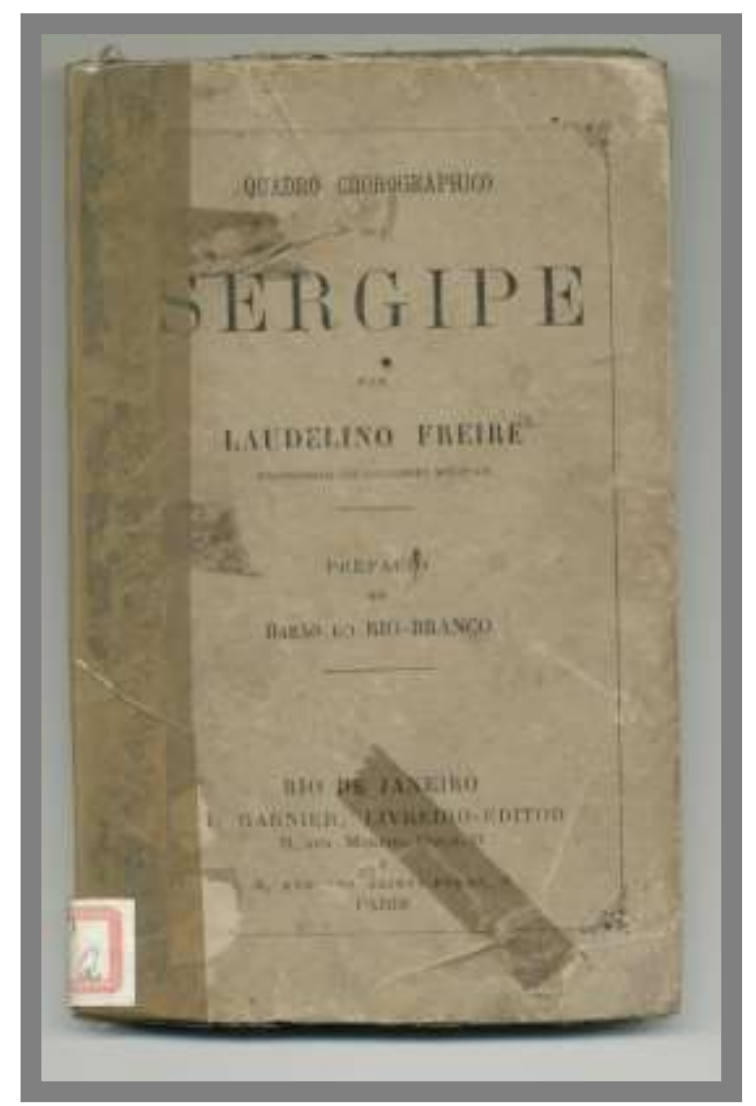

Fonte: Acervo da Biblioteca Central da Universidade Federal de Sergipe.

Na verdade, um grande intelectual que deve ser entendido conforme Sirinelli, que propõe duas acepções do termo considerando o caráter polissêmico da noção de intelectual, o aspecto polimorfo do meio dos intelectuais, e a imprecisão daí decorrente para se estabelecer critérios de definição do termo:

[...] uma ampla e sócio-cultural, englobando os criadores e os "mediadores" culturais, a outra mais estreita, baseada na noção de engajamento. No primeiro caso, estão abrangidos tanto o jornalista como o escritor, o professor secundário como o erudito. Nos degraus que levam a esse primeiro conjunto posta-se uma parte dos estudantes, criadores ou "mediadores" em potencial, e ainda outras categorias de "receptores" da cultura (SIRINELLI, 1996, p. 242). 
Conforme a nossa análise Laudelino Freire é um intelectual enredado na categoria sociocultural, na qual envolve o jornalista, o escritor, o professor secundário, o erudito, entre outros. Na sua biografia escrita por Guaraná (1925), é possível perceber os diversos artigos que escreveu, as revistas que criou e ainda a rede de relações que o mesmo mantinha com os intelectuais de sua época.

\section{Conteúdo da obra: Geografia ou Chorographia?}

Mesmo reunindo vários temas numa só obra - diferentemente dos seus contemporâneos, como afirmamos anteriormente - Laudelino Freire entendeu que o seu trabalho não podia ser chamado de Geografia, pelo que anunciou na página X:

A nossa primeira idéia foi de denominar este trabalho - Elementos para a Geographia geral de Sergipe: mas, como não tratamos do todo o vasto campo exigido pela palavra geographia e sim de partes fragmentorias, de descripção puramente regional, região que é território que constitue o Estado, julgamos mais cabível e expressivo o título de Quadro Corographico de Sergipe (FREIRE, 1898, p. X).

Vale enfatizar que, durante muito tempo, as Corografias fizeram parte do cenário do ensino da Geografia no Brasil. Freire acrescentou que (1898) Corografia é descrição de uma região, um país, de uma província ou de parte importante de um território; no dicionário de Jaime Seguier (1957) Chorographia é uma descrição de uma região ou de uma parte importante de território; para Dallabrida (2001), Corografia do Brasil estudava de forma separada, os aspectos físicos e humanos do Brasil e de cada Estado da federação brasileira, incluindo exercícios cartográficos e trabalhos escritos. Aqui deixamos clara a diferença entre Chorographia e Geografia à época.

O estudo dessa disciplina se dava a partir de apontamentos concebidos e organizados pelo próprio professor tendo em vista a raridade dos livros didáticos. É conhecido o caso de Aires de $\mathrm{Casal}^{1}$, cujo compêndio era resultado de apontamentos pessoais desse autor.

O conteúdo do livro do professor Laudelino Freire, apresentado em 119 páginas é divido em duas partes: física e política. Na primeira, o autor faz uma descrição geral dos aspectos físicos

\footnotetext{
${ }^{1}$ Manuel Aires de Casal (1945), escreveu "Corografia Brasílica", descrição minuciosa das províncias que então constituíam o Brasil; obra do mais alto valor histórico e geográfico para o seu tempo, e que ainda hoje merece ser consultada.

Quaestio, Sorocaba, SP, v. 19, n. 2, p. 455-470, ago. 2017.
} 
de Sergipe que envolvem: limites, posição astronômica, superfície, clima, condições de salubridade e a produção natural; em seguida o autor descreve os sistemas orográficos, nesográficos, hidrográficos, limnegráficos e, por último, o quadro da divisão civil, judiciária, policial e eclesiástica do Estado.

A segunda parte, descrição política de Sergipe envolve os seguintes temas: notícia histórica, relação dos cidadãos que governaram a Província de Sergipe, raça, língua, religião, população, forma de governo, poderes do Estado, representação, instrução pública, comércio, indústrias, força pública, capitania do porto, rendas do Estado, seguido de dois quadros: um das estações telegráficas do Estado e outro das agências do correio de Sergipe. Ainda dentro da segunda parte, vem a descrição da Comarca da capital e de seus municípios, abordando aspectos históricos, os limites do município, extensão territorial, aspectos físicos, clima, lavoura, população, instrução, topografia, o movimento comercial, estação telegráfica, sistema de iluminação, ruas, edifícios públicos, estabelecimentos industriais, jornais, arrabaldes e mapas das distâncias entre Aracaju e Rio de Janeiro. Todo esse nível de detalhamento é feito também com os municípios integrantes das Comarcas de Laranjeiras, Maroim, Capela, Própria, Gararu, Estância, Lagarto, Itabaiana, e Rio Real.

O autor menciona, nas notas de rodapé da obra, as fontes que nortearam a elaboração do seu trabalho, ao tempo em que mostra a polêmica e controversa discussão sobre os limites territoriais entre Sergipe e Bahia: “As graves questões que se têm suscitado entre os Estados limítrophes, as reclamações constantes das autoridades que ficam nas divisas contestadas [...]" (FREIRE, 1898, p. 1). O autor fez questão de citar os diversos estudiosos do assunto para que não ficasse entendido pelos seus leitores que o próprio Laudelino tivesse arbitrado sobre os tais limites. Os estudiosos citados por ele são: Felisbello Freire, Oliveira Campos, Francisco Viana, Coelho e Campos, Ivo do Prado, Ayres de Casal e Candido Mendes. Outras referências são destacadas: M. A de Souza, Memória da Capitania de Sergipe; F. S. do Salvador, História de Sergipe; F. Freire, História de Sergipe; Silva Travassos, Apontamentos Históricos e Topográficos de Sergipe; e, o Recenseamento Geral, de 1890.

O conteúdo do livro de Laudelino atendeu à proposição do Decreto no 231, de 9 de julho de 1897 (SERGIPE, 1900b, p. 55), aprovado um ano antes da publicação da citada obra, que estabeleceu o programa curricular para o ensino primário. Nesse programa, além da Geografia Geral e Cosmografia, estudava-se também Corografia do Brasil e, especialmente, de Sergipe. 


\section{4 "O juizo da imprensa"}

Adotamos o termo "O juizo da imprensa" que foi utilizado pelo livreiro - editor, $\mathrm{H}$. Garnier, da segunda edição do Quadro Chorográfico de Sergipe de Laudelino Freire, para fazer propaganda da obra e o espaço utilizado para tal estratégia foi a segunda capa da segunda edição.

"O juizo da imprensa" serviu para nos mostrar as representações que os jornais da época construíram acerca da primeira edição do mencionado livro. Assim, o livreiro-editor reuniu diversos artigos de jornais, sem nos informar a página dos mesmos, pois tal ação constituiu estratégia para aumentar a vendagem do livro, mostrando os comentários valorosos da imprensa a cerca do "Quadro Chorographico de Sergipe” de 1898.

A importância dessas notas recolhidas pelo livreiro-editor foram destacadas nessa parte do texto, e é por isso que as notas a seguir aparecem sem o número da página do jornal, porque não fizemos uma pesquisa nos jornais, quem a fez foi o livreiro-editor, em sua época, diante da sua necessidade de negociante. Nós como pesquisadores utilizamos as notas como dados importantes sobre o livro de Laudelino de Oliveira Freire.

Desse modo, as representações construídas pelos jornais e escolhidas pelo editor são críticas construtivas que valorizam a obra em questão, como: "É uma Chorographia bem feita desse Estado e não um simples quadro como o autor modestamente a denomina [...]" (JORNAL DO COMMERCIO, 29 ago. 1898).

O jornal A Notícia fez uma extensa reportagem a respeito do referido livro. Vale destacar alguns trechos:

O quadro Chorographico de Sergipe, pelo professor Laudelino Freire, é um trabalho didactico cuidadosamente elaborado e impresso com a máxima nitidez.

Poucos trabalhos didacticos poderão apresentar tão valioso attestado do seu merito como o que este traz, sabendo-se que as suas provas foram revistas pelo barão do Rio Branco, que em carta para o autor o louva com meritório tentamen [...] É, portanto, obra que excede o seu destino. Não só aos alumnos das escolas do Estado, como a todos os filhos delle e a quantos tenham de estudar detalhadamente a Chorographia do Brazil elle se recommenda [...] (A NOTÍCIA, 16 set. 1898).

O jornal A Cidade, também se manifestou a respeito do livro: "O livro está organizado com muito método, a linguagem é boa e o autor teve o máximo de escrúpulo na escolha dos dados de que se serviu" (A CIDADE, 31 ago. 1898). É importante notar que dentre essas representações, apenas uma é de um jornal sergipano, e que o autor a colocou sem a data. O Cotinguiba de Sergipe que diz: 
História de Sergipe e Quadro Chorographico de Sergipe, pelo Dr. Laudelino Freire. Fomos obsequiados por seu inteligente autor com um exemplar de cada uma d'estas obras ao ensino da mocidade sergipana.

[...] Consistem estes dois magníficos livros, a educação de um povo que pouco ou nada sabia dos seus principios, e onde a terra que pisava[...]

A maioria das representações foi de jornais do Rio de Janeiro: Jornal do Commercio, Noticia, Tribuna, Cidade do Rio, Gazeta da Tarde, Gazeta de Notícias, Jornal de Noticias, D’O Gallucho, Do Mercurio e Debate. Essas representações, selecionadas cuidadosamente pelo editor, foram importantes para o autor e sua obra, pois conforme Darnton (2010) estas são, na verdade, estratégias amplamente utilizadas pelo editor para campanhas de vendas de livros. Ainda evocando o autor é importante que o pesquisador esteja atento para as atitudes do editor "[...] em relação ao livro e o contexto de seu uso, estudando a maneira como eram apresentados - a estratégia do apelo, os valores invocados pela escolha de palavras - em todo tipo de publicidade, dos anúncios em jornais aos cartazes de rua” (DARNTON, 2010, p. 210).

Nesse sentido destacamos que o H. Garnier, livreiro-editor, não agiu aleatoriamente, quando elencou as notas de jornais no verso da segunda capa, da segunda edição. Ele estava utilizando uma de suas estratégias de publicidade para vender o livro do professor Laudelino Freire.

Por outro lado, o conjunto das notas de jornais dispostas no verso da segunda capa demonstra a rede de relações na qual Laudelino Freire estava envolvido e ainda o modo pelo qual os intelectuais brasileiros se relacionavam, pois conforme afirma Sirinelli, a "atração e a amizade e, ao contrário, a hostilidade e a rivalidade, a ruptura, a briga e o rancor desempenham igualmente um papel às vezes decisivo" (1996, p. 250), para se compreender a constituição de um campo intelectual. As representações construídas nos jornais mostraram como os letrados daquela época, através da disputa do campo intelectual, construíram os seus espaços e, desse modo, a sua história.

No tocante a circulação para Darnton (2010), é possível compreender a trajetória do livro, percebendo a sua dinâmica a fim de "[...] compreender como as ideias foram transmitidas sob forma impressa e como a exposição à palavra impressa afetou o pensamento e a conduta da humanidade. [...]” (p. 190). Nesse sentido o livro didático de Laudelino Freire teve uma importância fundamental para os estudantes sergipanos, uma vez que até a década de 1960, do século XX passamos quarenta e quatro anos sem uma nova produção didática, no âmbito da 
Geografia, sendo utilizados os livros produzidos no inicio da República, conforme revelou o estudo de Santos (2017), sobre o ensino da Geografia e os seus livros didáticos do século XIX ao XX.

Como fonte de pesquisa os livros repercutem os conteúdos, métodos adotados para o ensino em um determinado período, assim como as ideias pedagógicas, filosóficas e linguísticas que os fundamentam, por isso os mesmos instigam as pesquisas.

\section{Conclusão}

Durante muito tempo, as Chorographias fizeram parte do ensino da Geografia no Brasil. Como exemplo desse fato citamos Manuel Aires de Casal, autor da Chorographia Brasilica ou Relação Histórico-Geográfica do Reino do Brasil, que foi resultado de apontamentos pessoais desse autor.

Trata-se de uma obra de grande importância para a geografia brasileira, que "[...] conquistou grande prestígio, a tal ponto de ser quase um sacrilégio querer contestá-la" (VEIGA, 1984, p. 329). Tornou-se uma espécie de livro-eixo ${ }^{2}$, servindo de referência para muitos autores brasileiros. O livro do professor Laudelino de Oliveira Freire, O Quadro Chorographico de Sergipe, publicado em 1898, foi uma obra importante para a mocidade sergipana, considerando o tempo e o espaço em que foi produzido e considerando ainda, que foi um compêndio chorographico que foi adotado nas escolas públicas do Estado.

Pelo que analisamos, nos artigos de jornais integrantes da segunda edição de $\mathbf{O}$ Quadro Chorographico de Sergipe foi bastante comentado pela imprensa daquele tempo, sendo os comentários de forma elogiosa. Estes por sua vez foram a estratégia de venda utilizada pelo $\mathrm{H}$. Garnier livreiro - editor para a segunda edição.

É um livro que pela materialidade deixou evidenciar: formato, tamanho, sistematização e adequação dos conteúdos às normas vigentes. O programa curricular estabelecido para o ensino primário exigia que a Chorographia especialmente de Sergipe, fosse ensinada nas escolas. Assim,

\footnotetext{
${ }^{2}$ Expressão usada por Gláucio Veiga (1984, p. 329) ao fazer referência ao hábito de se transformar um livro em livro-eixo, fato comum no século XIX e que alcança o século XX. Para esse autor o livro-eixo não é propriamente o best-seller, característico de uma sociedade de consumo, mas um livro que serviu de modelo para a elaboração de outros.

Quaestio, Sorocaba, SP, v. 19, n. 2, p. 455-470, ago. 2017.
} 
o livro estudado estava acompanhando a mudança do tempo, mostrando os conteúdos que seriam importantes para a "mocidade sergipana".

É importante ressaltar que em função do interesse republicano de se construir, através da instituição escolar, a sedimentação e legitimação do novo regime da nação brasileira, o livro didático foi visto como difusor dos ideais republicanos, inculcando hábitos e comportamentos necessários àquela sedimentação e legitimação. O livro do professor Laudelino acompanhou a mudança do novo regime.

Considerando o novo regime, destacamos a utilidade dos conhecimentos geográficos os quais possibilitariam ao aluno amar a pátria, conhecer tanto suas glórias e os seus heróis, cujas virtudes deveriam servir de modelo, como as suas grandezas e riquezas naturais. Assim à "Geografia foi dada à mesma utilidade prática: conhecer e amar a pátria e no futuro defendê-la" (SOUZA, 1998, p. 179).

Vale ressaltar que para fazer essa análise, outros livros de Chorographia foram consultados como o de livro de Horacio Scrosoppi, Lições de Chorographia do Brasil (1911) e o de Elias do Rosário Montalvão, História e Chorographia de Maroim (1921), vimos que o desenvolvimento do conteúdo se deu da mesma forma que os demais. Conforme o estudo de Santos (2017), era uma tendência dos autores daquela época. Desse modo, O Quadro Chorographico de Sergipe possibilitou ao aluno o conhecimento da sua terra, através dos aspectos físicos, políticos e topográficos, cumprindo desse modo, a função defendida por Souza (1998) que era o conhecimento da sua terra, suas glórias e suas virtudes.

Convém ressaltar que o livro de Laudelino Freire teve uma importância fundamental para os estudantes sergipanos, uma vez que até a década de 1960, do século XX passamos quarenta e quatro anos sem uma nova produção didática, no âmbito da Geografia do Estado, sendo utilizados por professores e alunos, os livros produzidos no inicio da República, tais como: Chorographia do Estado de Sergipe (1897) de autoria de Luis Carlos da Silva Lisboa e Meu Sergipe: ensino da História e Chorographia de Sergipe (1916), de Elias do Rosário Montalvão de acordo com Santos (2017).

Não obstante essas observações sejam importantes, os impressos didáticos do século XIX devem ser interpretados sem que o analista assuma o viés do presentismo, evitando riscos como o de acusá-los de resumidos, imprecisos ou incompletos. É necessário compreendê-los sob as 
circunstâncias nas quais foram produzidos e saber que os mesmos cumpriram a sua função de civilizar os brasileiros à época em que circularam.

\section{Referências}

ANDRADE, Leila Angélica Oliveira de. Para formação do bom sergipano: um estudo do livro didático Meu Sergipe de Elias Montalvão (1916). 2002. Monografia (Conclusão do Curso de História).

Universidade Federal de Sergipe, São Cristóvão, 2002.

BARÃO DO RIO BRANCO. Prefácio. In: FREIRE, Laudelino de Oliveira. Quadro Chorographico de Sergipe. Rio de Janeiro: H. Garnier, 1898.

CARVALHO, Marta Maria Chagas de. Usos escolares do impresso: questões de historiografia. Cadernos de História e Filosofia da Educação, São Paulo, v. 3, n. 5, p. 165-177, jan./jun. 2000.

CASAL, Aires de. Chorographia brazilica ou relação histórico-geográfica do Reino do Brasil. 2. ed. São Paulo: Edições Cultura, 1945. Tomo I.

CHARTIER, Roger. A ordem dos livros: leitores, autores e bibliotecas na Europa entre os séculos XIV e XVIII. Brasília: Ed. UnB, 1999.

CHARTIER, Roger. Morte ou transfiguração do leitor? In: CHARTIER, Roger. Os desafios da escrita. São Paulo: UNESP, 2002.

DALLABRIDA, Norberto. A fabricação escolar das elites: o ginásio catarinense na primeira república. Florianópolis: Cidade Futura, 2001.

DARNTON, Robert. A questão dos livros: passado, presente e futuro. São Paulo: Cia. das Letras, 2010.

FREIRE, Laudelino de Oliveira. O quadro chorographico de Sergipe. Rio de Janeiro: H. Garnier, 1898.

FREIRE, Laudelino de Oliveira. O quadro chorographico de Sergipe. 2. ed. Rio de Janeiro: H. Garnier, 1902.

GUARANÁ, Manoel Armindo Cordeiro. Diccionario bio-bibliographico sergipano. Rio de Janeiro: [s.n.], 1925.

GINZBURG, Carlo. A micro-história e outros ensaios. Rio de Janeiro: Bertrand Brasil, 1989.

MUNAKATA, Kazumi. Produzindo livros didáticos e paradidáticos. 1997. Tese (Doutorado em Educação) - Pontifícia Universidade Católica de São Paulo, São Paulo, 1997.

NUNES, Maria Thetis. História da educação em Sergipe. Rio de Janeiro: Paz e Terra, 1984.

SANTOS, Vera Maria dos. O livro didático de geografia: Sergipe, do século XIX ao século XX. Aracaju: Diário Oficial do Estado de Sergipe-EDISE, 2017.

SEGUIER, Jaime. Dicionário prático ilustrado. Porto: Lello \& Irmão, 1957.

SERGIPE (Estado). Decreto no 231, de 9 de julho de 1897. Reforma o Ensino da Instrucção Publica. Compilação das leis e decretos e regulamentos do Estado de Sergipe 1897-1898. Aracaju: Typ Do "O

Estado de Sergipe", 1900b. v. 4

SERGIPE (Estado). Lei $\mathbf{n}^{\mathbf{0}} \mathbf{2 5 7}$, de 25 de novembro 1897, Anexa a cadeira de Chorographia à de Geographia. Compilação das leis e decretos e regulamentos do Estado de Sergipe 1897-1898. Aracaju: Typ Do "O Estado de Sergipe", 1900a. v. 4. 
SILVA, José Calazans Brandão da. Aracaju e outros temas sergipanos. Aracaju: Governo de Sergipe FUNDESC, 1992.

SIRINELLI, Jean-François. Os intelectuais. In: RÉMOND, René. Por uma história política. Rio de Janeiro: UFRJ/Fundação Getúlio Vargas, 1996. p. 231-263.

SOUZA, Rosa Fátima de. Templos de civilização: a implantação da escola primária graduada no Estado de São Paulo (1890-1910). São Paulo: Ed. da Unesp, 1998.

VEIGA, Gláucio. História das idéias da Faculdade de Direito do Recife. Recife: UFPE, 1984. v. 4.

WUO, Wagner. O ensino da Física na perspectiva do livro didático. In: OLIVEIRA, Marcos Aurélio Taborda de; RANZI, Serlei Maria Fischer Ranzi. (Org.). História das disciplinas escolares no Brasil: contribuições para o debate. Bragança Paulista: EDUSF, 2003.

\footnotetext{
Vera Maria dos Santos - Universidade Tiradentes - Unit. Aracaju | SE | Brasil. Contato: veramstos@yahoo.com.br

Simone Silveira Amorim - Universidade Tiradentes - Unit. Aracaju | SE | Brasil. Contato: amorimsimone@ hotmail.com

Éverton Gonçalves de Ávila - Universidade Tiradentes - Unit. Aracaju |SE | Brasil. Contato: everton.vila12@gmail.com
}

Artigo recebido em: 4 maio 2017 e aprovado em: 20 jul. 2017. 